\title{
Giacomo Casanova oder das Europa der Liebe
}

An dieser Stelle schließen wir unsere Beschäftigung mit dem ausgehenden 15. und dem beginnenden 16. Jahrhundert und damit zugleich mit der ersten Phase beschleunigter Globalisierung ab. Wir haben in dieser Phase Reiseberichte und Reiseliteratur sehr unterschiedlicher Herkunft, Genese und Machart kennengelernt und gleichzeitig einen Einblick in die verschiedenen Dimensionen und Bewegungen des frühneuzeitlichen Reiseberichts erhalten. Wir wollen in unserem dritten Teil der Vorlesung ja nicht eine Exhaustivität der Herangehensweise pflegen, sondern eine Repräsentativität der Bezugstexte - und an dieser Stelle glaube ich, gute Gründe dafür zu haben, das frühneuzeitliche Kapitel unserer Vorlesung abzuschließen.

Machen wir daher einen beherzten Sprung in die zweite Phase beschleunigter Globalisierung von der Mitte des 18. bis zum Beginn des 19. Jahrhunderts. Wir werden dabei auf eine nicht geringere Vielfalt an Texten stoßen, die uns die Breite an reiseliterarischen Formen, aber auch die Entwicklungen der Gattung auf diesem Gebiet näherbringen werden. Dabei werden wir so manche Überraschung erleben.

Auch für diese zweite Phase werde ich bewusst repräsentative Beispiele wählen, die es erlauben, gleichzeitig einen panoramatischen Überblick über reiseliterarische Formen und Entwicklungen zu erhalten und dabei monographische Studien zu betreiben, die uns einen Autor oder eine Autorin etwas ausführlicher vorführen. Gemäß der veränderten historischen Einstellung verändert sich aber auch der Fokus nationaler Herkunft der Reiseberichte, waren es nun doch nicht mehr Spanien und Portugal, sondern vor allem Frankreich und England, die als Führungsmächte dieser zweiten Phase beschleunigter Globalisierung ihren Stempel aufdrückten. Das Szenario der Reiseliteratur hat sich also gewandelt - und mit ihm auch das Skript unserer Vorlesung. Dabei wird Sie vielleicht gerade unser erster Autor in Erstaunen setzen.

Denn es wird Sie wohl überraschen, daß wir uns im monographischen Teil unserer Vorlesung, also jenen Bereich, in dem wir uns mit einzelnen Autorinnen und Autoren auseinandersetzen, ausgerechnet mit einem Schriftsteller beschäftigen, der für viele Dinge geradezu sprichwörtlich bekannt ist, aber eigentlich nicht unter der Rubrik 'Reiseliteratur' geführt und katalogisiert wird. So mag es als verwegen erscheinen, an dieser Stelle einen Schriftsteller zu behandeln, der auch auf den ersten Blick im Grunde nichts mit der epochentypischen Bewegung der Globalisierung zu tun hat, sondern eher für die Sitten der Zeit und insbesondere die Formen intimen Lebens stehen kann. Denn das Thema Liebe wird bei ihm groß geschrieben. 
Und doch ist zum einen das vielbewegte Leben Giacomo Casanovas, der sich den Ehrentitel eines Chevalier de Seingalt recht selbstbewusst erwählte und den sein galant, den galanten Busen, dabei bestimmt auch im zwinkernden Auge hatte, nicht von vielfältigsten Reisen zu trennen, die ihn an verschiedene Enden des damaligen Europa führte. Denn Casanova liebte die erlesene Gesellschaft seiner Zeit und kostete ihren weiblichen Charme aus, bis er jeweils an andere Orte fliehen musste, um aus Sicherheitsgründen gleichsam die Tapete seiner Innenräume auszuwechseln. Zum anderen aber lebte und liebte er nicht nur dieses Leben, sondern schrieb es auch im avancierten Alter nieder, wurde also zum Verfasser der Geschichte meines Lebens, mit der Giacomo Casanova seine Laufbahn schriftstellerisch krönte und zu einem gelungenen Abschluss führte. So ging er ein in jene Hall of Fame der Liebenden, die der Liebe und dem Gotte Amor, aber nicht der Geliebten opfern, und zugleich in jene der Reisenden, hatte er gegen Ende seines Lebens doch einen guten Überblick über die Fürstenhöfe, die sich über fast ganz Europa verstreuten, und die unterschiedlichsten Landschaften, die er auf seinen Fahrten und Fluchten durchquerte. Es kann kein Zweifel daran bestehen: Giacomo Casanova ist sicherlich eine der faszinierendsten Figuren des großen Zeitalters der Aufklärung.

Die Figur des Giacomo Casanova wird uns mit zwei durchaus miteinander in Zusammenhang befindlichen Dimensionen in Berührung bringen, die auf sehr intensive Weise mit dem Phänomen des Reisens in Verbindung stehen. Zum einen ist das Reisen stets, in einem ganz generellen Sinne, einem Vektorenfeld des Begehrens zuzuordnen, beruht also immer auch auf einem Begehren des Anderen, anderer Landschaften, anderer Reichtümer, anderer Erfahrungen und anderer Menschen. In der Bewegung des Reisens und des oder der Reisenden verknüpfen sich Motion und Emotion, verbinden sich also die physisch-topographische Bewegung mit der inneren Gefühlsbewegung, wobei diese emotionale Seite des Reisens nicht als sekundär bewertet werden sollte. Denn das Begehren ist eine mächtige Antriebskraft in der affektiven Ökonomie des Menschen. ${ }^{1}$

Zum anderen hat eben dieses Begehren und seine Ökonomie auch sehr viel damit zu tun, dass das Reisen nicht selten auch mit dem Sammeln einhergeht. ${ }^{2}$ So sammeln wir beim Reisen oder Wandern beispielsweise kleinere Steine und Andenkenplättchen auf unserem Spazierstock, wie wir dies heute noch bei älteren Semestern etwa in den Alpen oder im Schwarzwald bewundern können.

1 Vgl. zu diesem Komplex Hindemith, Gesine / Stöferle, Dagmar (Hg.): Der Affekt der Ökonomie. Spekulatives Erzählen in der Moderne. Berlin - Boston: Walter de Gruyter 2018; sowie Bidwell-Steiner, Marlen: Das Grenzwesen Mensch. Vormoderne Naturphilosophie und Literatur im Dialog mit postmoderner Gendertheorie. Belin - Boston: Walter de Gruyter 2017.

2 Vgl. Sánchez, Yvette: Coleccionismo y literatura. Madrid: Ediciones Cátedra 1999. 
Oder wir sammeln bei unseren Reisen Erfahrungen und Erlebnisse, bisweilen aber auch Reiselektüren, die sich für uns in Gemeinschaft mit bestimmten Landschaften einprägen. Und schließlich sammeln wir auch Kontakte mit anderen Menschen, wobei dies bei Casanova sicherlich im Bereich intimer zwischenmenschlicher Beziehungen ganz zweifellos der Fall war. Giacomo Casanova kann aus der Sicht dieser affektiven Ökonomie ${ }^{3}$ folglich sehr wohl als ein passionierter, leidenschaftlicher Sammler bezeichnet werden.

Bevor wir uns aber mit diesen wichtigen Aspekten auseinandersetzen, sollten wir uns zunächst mit einigen Stationen im Leben des Giacomo Casanova beschäftigen, um auf diese Weise zunächst einmal einen Überblick über biographische Facetten seines Leben-Schreibens zu erhalten. Gleich vorausgeschickt sei, dass es dem Lebenslauf des Venezianers wahrlich nicht an Bewegung fehlte; und doch war dies zugleich repräsentativ für die Blütezeit des europäischen 18. Jahrhunderts und eine gewisse Gesellschaftsklasse, welche von einem hohen Grad an Internationalisierung sowie an internationalem Austausch geprägt war, wie wir ihn vielleicht erst in unserer aktuellen Epoche wieder erreicht haben. Im 18. Jahrhundert freilich beschränkte sich dies auf eine zahlenmäßig kleine Elite.

Giacomo Girolamo Casanova wurde an einem 2. April 1725 in Venedig als Sohn des Gaetano Casanova und dessen Frau Zanetta geboren. Seine Eltern waren beide Schauspieler, eine für das künftige Leben des jungen Mannes vielleicht nicht ganz unbedeutende Tatsache. Die Lagunenstadt, so ließe sich sagen, war seine Heimat und blieb trotz aller Fluchten, Reisen und Verbannungen im Grunde der Mittelpunkt seines gesamten Lebens. Denn nach Venedig trieb es ihn von allen 'Ausflügen' und Exkursionen, so weit sie ihn auch immer führen mochten, stets wieder zurück. Es verbitterte ihn im Alter sehr, noch ein letztes und endgültiges Mal aus der Stadt mit ihren Kanälen und den vielen mysteriösen Palästen verbannt worden zu sein.

Als neunjähriger Junge kam Giacomo - sein Vater verstarb bereits, als er acht Jahre alt war - in ein Internat ins nahe gelegene Padua. ${ }^{4}$ Er erwies sich rasch als außergewöhnlich begabt und eignete sich schnell immer neues Wissen an, so dass er bereits 1737 an der ehrwürdigen Universität von Padua immatrikuliert wurde. Nach fünfjährigem Studium erwarb er dort den Grad eines Doktors der Rechte, auch wenn wir nicht moderne Maßstäbe an das damalige Bildungssystem

3 Vgl. hierzu Schlünder, Susanne / Stahl, Andrea (Hg.): Affektökonomien. Konzepte und Kodieerungen im 18. und 19. Jahrhundert. Paderborn: Wilhelm Fink 2018.

4 Vgl. zur Biographie u. a. Loos, Erich: Einleitung. In: Casanova Chevalier de Seingalt, Giacomo: Geschichte meines Lebens. Mit einem Essay von Peter Quenell „Der Verführer in der Literatur“. Herausgegeben und eingeleitet von Erich Loos. Erstmals nach der Urfassung ins Deutsche übersetzt von Heinz von Sauter. Bd. 1. Berlin: Propyläen-Verlag 1985, S. 37-60. 


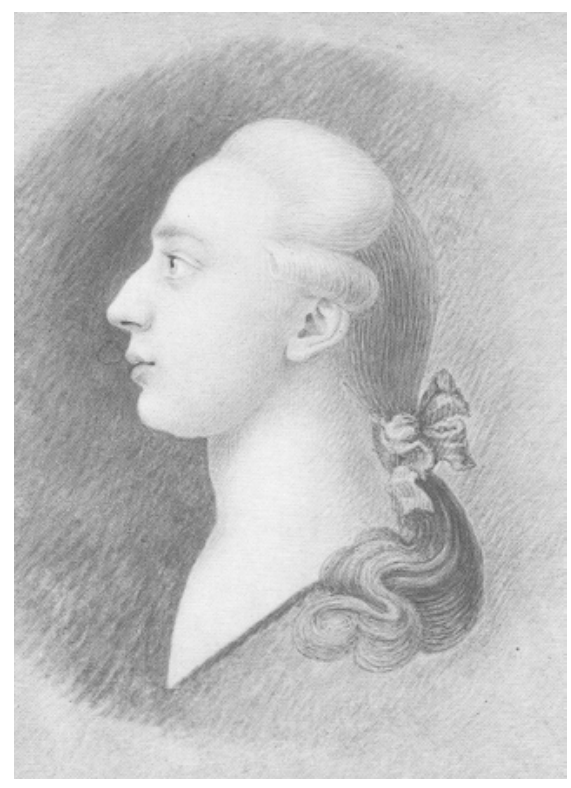

Abb. 53: Giacomo Girolamo Casanova (Venedig, 1725 - Dux in Böhmen, 1798).

anlegen sollten. Im Zentrum seiner Studien wie auch der seiner Kommilitonen stand die Lehre von den Sieben Freien Künsten, wobei als Grundstudium die Fächer Grammatik, Rhetorik und Dialektik gelehrt wurden. Der junge Casanova absolvierte alles mit Bravour.

Es war keineswegs ungewöhnlich, dass Casanova bereits als Siebzehnjähriger sein Studium mit dem Doktortitel, als Doktor beider Rechte (des weltlichen wie des kanonischen Rechtes) abschließen konnte. Seine Mutter wie seine Großmutter wollten die Zukunft des jungen Mannes als Rechtsgelehrter im Dienste der katholischen Kirche sichern; daher erhielt er 1740 die Tonsur und 1741 die niederen Weihen: Aus dem Studenten wurde der Abate Casanova. Diesen Abbé - und wir wissen, welche Rolle die Abbés in der Französischen Revolution spielen sollten nun empfahl die Mutter zunächst einem Bischof in Kalabrien: Er reiste 1743 nach Martirano bei Cosenza, was den Beginn eines durchaus abenteuerlichen Wanderlebens markierte: Denn das bescheidene Bergstädtchen in Kalabrien vermochte ihn nicht zu halten. Casanova hatte andere Pläne. So begab er sich von Neapel nach Rom, wo er als Sekretär des spanischen Gesandten, des Kardinals Aquaviva, eine sichere Laufbahn hätte beginnen können. Er verfügte zudem über beste Beziehungen zum Papst, der ihn zum 'apostolischen Protonotar' ernannte sowie zum Ritter des Goldenen Sporns, was ihm die Führung des Titels eines Chevalier ermöglichte. Alles hätte so gut in seinem Leben laufen können: Wenn nicht 


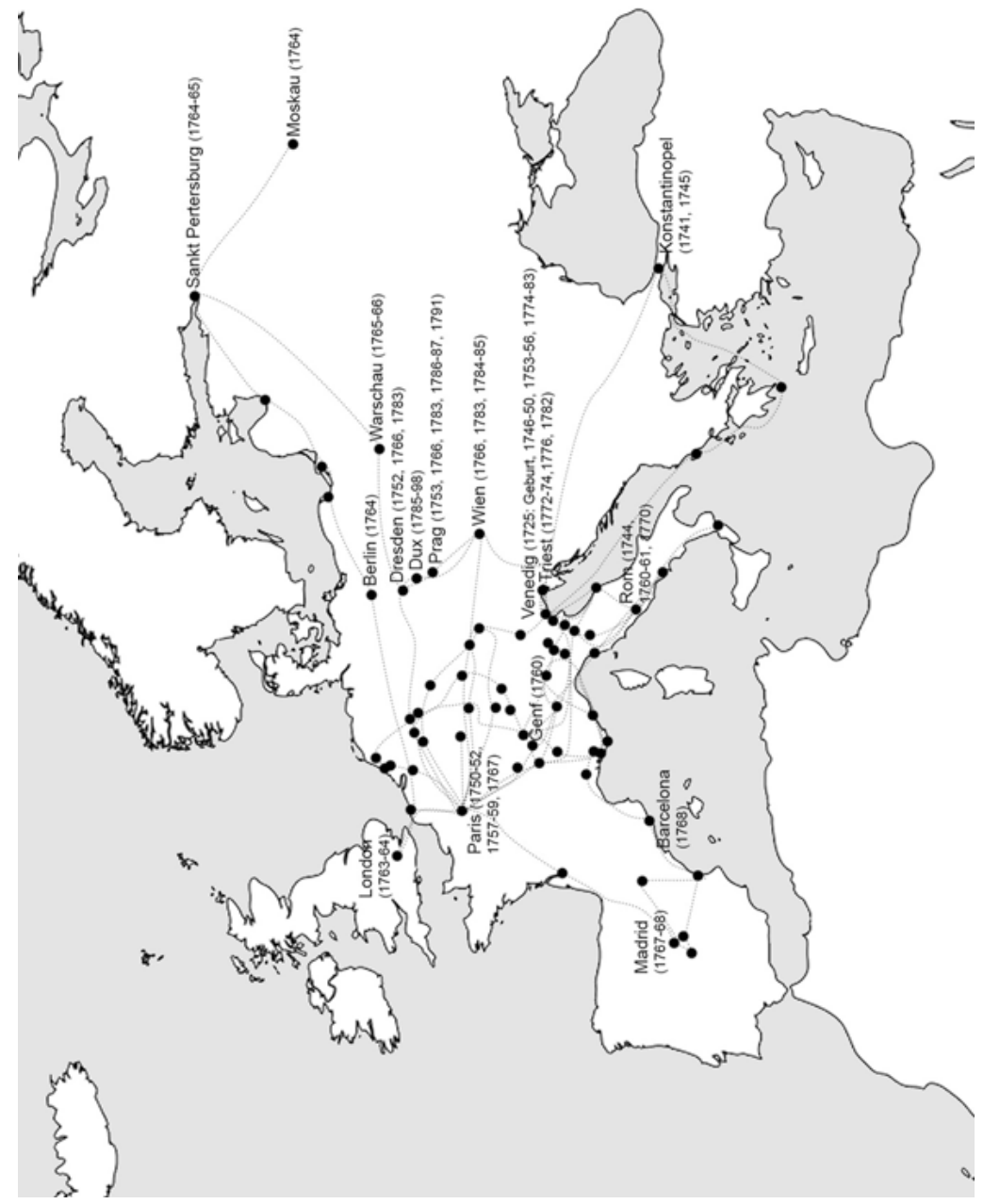

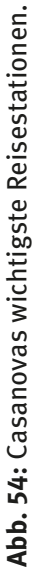


eine Entführungsgeschichte seinen weiteren Aufstieg unterbrochen hätte: Der junge Mann musste Rom fluchtartig verlassen.

Casanova gelangte nach Bologna, wo er sich 1744 entschloss, das geistliche Gewand abzulegen und sein Glück - ganz im Sinne von Stendhals Le rouge et le noir - nunmehr als Soldat zu versuchen. Doch bereits 1745 verzichtete er nach Erfahrungen im Dienste der Republik Venedig auf der Insel Korfu und wohl auch in Konstantinopel auf eine Fortsetzung seiner eher tristen Soldatenlaufbahn. Er träumte von höheren Aufgaben, für die er sich empfehlen wollte.

Casanova lebte nun zunächst in Venedig vom Geigenspiele und hatte dann das Glück, den Senator Bragadin von einer Art Schlaganfall zu heilen. Dieser glaubte in dem geschickten Casanova einen Vermittler zum Überirdischen gefunden zu haben und behandelte ihn wie einen Sohn, so dass ihm nun alle Mittel für ein gutes Leben zur Verfügung standen. Zwischen 1746 und 1749 scheint er alle in ihm schlummernden Fähigkeiten als Spieler und Verführer vervollkommnet $\mathrm{zu}$ haben. Sein Lebenswandel wurde der venezianischen Inquisition verdächtig, so dass er 1749 Venedig verließ, mehrere oberitalienische Städte besuchte und schließlich ins französische Lyon reiste, wo er Freimaurer wurde. Das Schicksal hatte es mit Casanova anders gemeint.

Schon 1750 finden wir ihn erstmals in Paris, wo es ihm nicht schwerfiel, bald Zugang zu den vornehmsten Zirkeln der Stadt zu finden. 1752 ging er dann nach Dresden, um dort seine als Schauspielerin tätige Mutter zu besuchen. Für deren Theatergruppe schrieb Casanova die italienische Fassung einer französischen Oper sowie eine Parodie auf eine Tragödie von Racine. Beide Werke wurden mit Erfolg aufgeführt. Vom damaligen Elbflorenz reiste er weiter nach Wien und schließlich wieder nach Venedig, wo er nach zwei Jahren müßiggängerischer Abenteuer am 26. Juli 1755 wegen Beschäftigung mit den Geheimwissenschaften, wegen Beleidigung der Religion und als Freimaurer verhaftet und unter den berüchtigten Bleidächern, den sogenannten 'Bleikammern' des Dogenpalastes, eingekerkert wurde. Doch er plante minutiös seine Flucht. Sein Plan gelang: Am 31. Oktober 1756 glückte ihm sein sensationeller Ausbruchsversuch. Casanova hatte seinen sprichwörtlichen Lebenswillen und Überlebenswillen, aber auch seine Intelligenz tatkräftig unter Beweis gestellt. Auch wenn sein Buch über seine Flucht erst sehr viel später, im Jahre 1788, erscheinen sollte: Die europäische Öffentlichkeit wurde auf ihn aufmerksam.

Casanova beschloss, wieder nach Paris zu reisen, wo der durch seinen spektakulären Ausbruch berühmt Gewordene dank seines außerordentlichen Organisationstalents als Mitbegründer der Königlichen Lotterie und durch das Vertrauen der Marquise d'Urfé zu einem reichen Mann wurde. Wieder einmal schien Casanova in einer beneidenswerten Stellung zu sein, die ihm alle Chancen für ein glückliches und ruhiges Leben eröffnete. Doch auch diesmal schlug 
er die Chance wieder aus: Er genoss seine Stellung in vollen Zügen und bewies erneut seine Spielernatur. Doch durch seine Aktivitäten geriet er bald schon erneut in Verdacht, so dass er es vorzog, Ende 1759 die französische Hauptstadt wieder zu verlassen. Ein unstetes Nomadenleben zwischen verschiedensten europäischen Städten schloss sich an: Giacomo Casanova wird auf seinen Reisen durch Frankreich, Deutschland, die Schweiz oder die Niederlande für seine vielfältigen Liebschaften berühmt und berüchtigt.

Diese bewegte Phase endete mit seinem Aufenthalt in London von Juni 1763 bis März 1764. Bei Casanova verstärkte sich das Bewusstsein, den Höhepunkt seines Lebens bereits überschritten $\mathrm{zu}$ haben. Sein Weg führt den Venezianer auch zu Friedrich den Großen an den preußischen Hof zu Potsdam und Berlin; doch das Angebot Friedrichs, wohlgemerkt Erzieher an der Kadettenakademie der preußischen Armee $\mathrm{zu}$ werden, lehnt Casanova schließlich ab und versucht sein Glück vergeblich am Hofe der Zarin Katharina II. von Russland. Obwohl sich der Venezianer neun Monate am Hofe in St. Petersburg aufhält, kann ihm die Zarin doch keine adäquate Stellung am Hofe verschaffen.

Seine nächste Station ist Warschau, wo er das Duell um Liebeshändel mit dem polnischen Kronkämmerer Graf Branicki wie dieser schwerverletzt übersteht, so dass er im Sommer 1766 fluchtartig Polen wieder verlassen muß und nach Wien weiterzieht. Dort aber gerät er mit der sogenannten 'Keuschheitskommission' in Konflikt und wird des Landes verwiesen. Ein erneuter kurzer Aufenthalt in Paris endet wiederum mit der Ausweisung im November 1767, wonach er sich nach Spanien wendet, dessen rigoroses gesellschaftliches Klima ihm aber missfällt. In Madrid wird er bald wegen unerlaubten Waffenbesitzes kurzzeitig eingekerkert. Liebeshändel brachten ihm in Barcelona 1768 eine Kerkerhaft von 42 Tagen ein, die er unter anderem zur Niederschrift einer umfangreichen Verteidigung der venezianischen Politik gegen französische Historiographen nutzte. Casanova dachte an seine geliebte Lagunenstadt und sehnte sich nach ihr.

Das Werk erschien 1769 unter falscher Verlagsangabe in Lugano, wobei diese Veröffentlichung ihm die Gunst der venezianischen Regierung gewinnen und die Rückkehr in die Heimatstadt ermöglichen sollte. In der Folge verfasst Casanova eine Fülle literarischer Arbeiten, die sich mit verschiedensten, auch naturwissenschaftlichen Themen befassen. Er hält sich in der Nähe des Territoriums der Republik Venedig auf, um dem von ihm ersehnten Ruf der Serenissima sofort folgen zu können; doch dieser Ruf lässt auf sich warten. So arbeitet er 1771 in Florenz an einer Übersetzung der Ilias, von der mehrere Teile erscheinen, und lebt dann von 1772 bis 1774 mit einer großen historiographischen Arbeit über Polen beschäftigt - unter anderem in Triest. Durch Agentendienste sucht er die Gunst der 
venezianischen Inquisition für sich zu gewinnen und die venezianische Regierung für sich einzunehmen. Dies gelingt endlich im November 1774, als ihm die ersehnte Begnadigung zuteil wird: Casanova darf am 14. September 1774 nach Venedig zurückkehren.

In Venedig lebt Casanova zunächst zurückgezogen; er arbeitet unter anderem als Spitzel für die venezianische Staatsinquisition. Seine Spitzelberichte unterzeichnet er, wenn man der Literatur glauben darf, mit dem Pseudonym Antonio Pratolini. ${ }^{5}$ Doch 1782 verfasst er nach einem Wortwechsel mit einem Patrizier eine scharfe Satire, was ihm die abermalige und endgültige Verbannung aus Venedig einträgt. Sein Wanderleben setzt wieder ein, das ihn für kurze Zeit nach Paris und schließlich nach Wien führt, wo er 1784 Sekretär des venezianischen Gesandten Foscarini wird.

Nach dessen Tod bietet ihm der junge Graf von Waldstein die Stelle eines Bibliothekars in seinem Schloss im nordböhmischen Dux an: Im September 1785 übernimmt Casanova sein neues Amt, unterhält eine weitläufige Korrespondenz mit zahlreichen europäischen Persönlichkeiten, widmet sich wissenschaftlichen und literarischen Arbeiten und beginnt um 1790 mit der Niederschrift seiner Memoiren. Diese umspannen insgesamt die Jahre zwischen 1733 und 1774, mithin vier bedeutsame Jahrzehnte der Epoche der Aufklärung und des Rokoko, die uns Casanova in seiner Histoire de ma vie als ein herausragender Zeitzeuge kommentiert und nahebringt. Ein Leben, das sich wie ein Reisebericht liest, kommt zu seinem schriftstellerischen Ende.

Giacomo Casanova blieb der Stadt Venedig mit allen Fasern seines Lebens verbunden. Das damals recht freizügige Klima der Stadt der Inseln formte und prägte ihn zutiefst. Zugleich kann er als das bezeichnet werden, was man im 18. Jahrhundert einen cosmopolite oder im Deutschen einen 'Weltbürger' nannte, obwohl er Europa, die Alte Welt, nie verließ. Der illustre Venezianer war ein typischer Vertreter jener französisch gebildeten und französischsprachigen Elite, die sich in der internationalen République des Lettres zwischen den Ländergrenzen hin- und herbewegte. Unter diesem Gesichtspunkt war Casanova sehr wohl eine repräsentative Figur für die Eliten des europäischen Jahrhunderts der Aufklärung.

Als Giacomo Casanova mit der Niederschrift seiner in französischer Sprache abgefassten Histoire de ma vie im Jahre 1789 oder spätestens 1790 begann, blickte er auf einen langen Zeitraum zurück, den er ganz im Sinne der Memoiren seiner Zeit - wie auch der modernen Autobiographie, die mit Jean-Jacques

5 Vgl. Bolitho, William: Zwölf gegen das Schicksal - Die Geschichte des Abenteuers. Traunstein: Müller und Kiepenheuer 1946, S. 78. 
Rousseaus Confessions ihren eigentlichen Beginn und ersten Höhepunkt erst wenige Jahre zuvor erreicht hatte - inhaltlich immer stark an großen Persönlichkeiten, denen er begegnet war, ausrichtete, zugleich aber natürlich gerade den amourösen Geschichtchen und Geschichten einen großen Teil seiner verschriftlichten Aufmerksamkeit widmete. Casanova war auch in diesem Sinne ein Kind seiner Zeit.

Man hat mit Rückgriff auf seine eigene Formulierung auch zu Recht von einer genießenden Niederschrift der Memoiren gesprochen, denn Casanova hat ganz offensichtlich diese Niederschrift und die Erinnerungen und Ausgestaltungen, die er gegen Ende seines Lebens zu Papier brachte, sehr genossen. Mit einer Wendung von Roland Barthes könnte man diese Memoiren, diesen Reisebericht seines Lebens, ganz in das Zeichen einer 'Lust am Text' stellen, die alle Seiten seines Berichts durchdringt.

Zugleich entsteht das, was man gleichsam den autobiographischen Pakt sowie auch den reiseliterarischen Pakt dieses Textes nennen könnte: Der Autor steht mit seinem Namen dafür ein, dass es sich bei dem Ich, dem wir in diesem Buch begegnen und das als Verfasser auf dem Buchdeckel steht, tatsächlich um den realen, textextern referentialisierbaren Autor mit Haut und Haaren handelt. Nun gut, auf diese Problematik kommen wir noch zurück; wir hatten sie ja auch bereits in der sechsten Dimension unseres systematischen Teiles der Vorlesung erörtert.

Wichtig aber ist für uns an dieser Stelle, dass es in der Reiseliteratur wie in der Autobiographie und Memoirenliteratur kein monolithisches Ich gibt, sondern dass dieses Ich in mindestens zwei Ichs sich aufspaltet, die miteinander in engster Verbindung stehen: Erstens in das erzählende Ich, das sich an seine früheren Wanderungen und Erfahrungen erinnert, und zweitens in das erinnerte Ich, das die Situationen erlebt und durchlebt, welche später dann vom erzähelnden Ich in schriftlicher Form festgehalten werden. Diese beiden Figurationen des Ich finden sich sowohl in der Reiseliteratur als auch in der Memoirenliteratur und 'klassischen' Autobiographie als gattungsspezifische Grundstruktur.

Eben dies ist auch in Giacomo Casanovas Histoire de ma vie der Fall, sogar in einem sehr starken Maße, da sich in der Tat bei ihm die autobiographischen und die reiseliterarischen Gattungsspezifika gleichsam wechselseitig verstärken. Die Textdiegese, also der raum-zeitliche Bereich, der in der Geschichte meines Lebens ausgespannt wird, endet also keineswegs mit dem Jahre 1774, der Rückkehr nach Venedig, in der Casanova im Grunde jene zweite Phase zu Ende gehen sah, von der zu berichten und zu erzählen dem alten Mann noch Freude machte. So können Sie es eigentlich in allen literaturwissenschaftlichen Darstellungen lesen, die zu den Memoiren des Venezianers verfasst wurden. Doch dabei wird ein Wesentliches übersehen: Denn 'natürlich' wird die Situation des 
schreibenden, des erzählenden Ich immer wieder eingeblendet, wobei diese Position auch durch die Reflexionen, die metatextuellen Einschübe, im Text immer wieder in besonderem Maße erscheint und die entsprechenden historischen, kulturellen, erotischen und anderen Erfahrungen einbringt. Wir sehen so ein gewiss stilisiertes schreibendes, erzählendes Ich bei der Arbeit, ständig im Begriff, sich über lange Zeiträume seines Lebens hinweg zu erinnern, so dass diese Phase der langen Niederschrift im Alter auf dem nordböhmichen Schloss Dux im Text selbst sehr wohl präsent ist. Bis zu seinem Tode war Casanova mit der Fertigstellung und Überarbeitung seiner Memoiren beschäftigt.

Vielleicht sollten wir am besten mit dem Anfang dieses sehr umfangreichen zwölfbändigen Werkes beginnen, das erst lange Zeit nach dem Ableben des Verfassers zunächst in deutscher Übersetzung ab 1822 bei Brockhaus in Leipzig $\mathrm{zu}$ erscheinen begann. Denn die Veröffentlichungsgeschichte der Memoiren ist durchaus kurios und endet keineswegs mit dem schließlich erfolgenden Aufkauf des französischen Manuskripts des Italieners für einen hohen Millionenbetrag durch die Bibliothèque Nationale von Paris.

Der große Erfolg dieser recht problematischen Erstausgabe, von der aus paradoxerweise wieder zurück ins Französische übersetzt wurde - die Nachfrage war so groß, dass im Laufe der Zeit in Frankreich wie in Deutschland jeweils mehr als einhundert verschiedene Ausgaben erschienen - stellte alle Erwartungen in den Schatten und verankerte bereits frühzeitig den Namen des frankophilen Italieners im kollektiven Gedächtnis der abendländischen Welt als eine Art Prototyp oder repräsentative Figur des Verführers in der Literatur. War es wirklich dieses Bild, das Casanova von sich selbst transportiert sehen wollte? Viel gäbe es dazu zu sagen; doch sollten wir uns zunächst einmal mit der Vorrede Giacomo Casanovas - übrigens in einer ausgezeichneten deutschsprachigen Ausgabe - beschäftigen.

Ihr ist als Motto ein unvollständiges Cicero-Zitat vorangestellt, das am Ende der Vorrede erneut bemüht wird, so dass eine Art Kreisstruktur entsteht und dieses Motto zusätzlich in seiner Bedeutung herausgehoben wird: „Wer sich nicht selbst kennt, weiß gar nichts.“ Damit ist das zentrale Motiv der Selbsterkenntnis, der Selbsterfahrung von Beginn an in den Text eingeblendet. Vielleicht wäre hier eher das Bild zu suchen, das Casanova philosophischerweise von sich am liebsten sehen wollte. Nach diesem Motto heißt es dann:

Ich erkläre meinem Leser von vornherein, daß ich bei allem, was ich zeit meines Lebens an Gutem oder Bösem getan habe, sicher bin, entweder verdienstvoll gehandelt oder gesündigt zu haben, und daß ich mich deshalb für ein mit freiem Willen begabtes Wesen halten muß. [...] Ich glaube an die Existenz eines unkörperlichen Schöpfergottes, der Herr alles Gestaltgewordenen ist. Der Beweis dafür, daß ich nie daran gezweifelt habe, ist für mich die Tatsache, daß ich stets auf seine Vorsehung zählte, in allen meinen Nöten durch das Gebet Zuflucht bei ihm suchte und auch stets erhört wurde. [... ] 
Der Leser, der zum Nachdenken neigt, wird aus diesen meinen Erinnerungen ersehen, daß ich nie auf ein bestimmtes Ziel zusteuerte und deshalb nur dem System folgte wenn es überhaupt eines ist -, mich dahin treiben zu lassen, wohin der Wind blies. Wie viele Wechselfälle birgt doch diese Unabhängigkeit von jeglicher Methode in sich! Meine Mißgeschicke haben mir ebenso wie die Glücksfälle gezeigt, daß auf dieser gleichermaßen körperlichen wie moralischen Welt das Gute aus dem Bösen hervorgeht, wie das Böse aus dem Guten. Meine Irrwege werden den Nachdenklichen die entgegengesetzten Pfade weisen oder sie die hohe Kunst lehren, sich stets im Sattel zu halten. Es gilt nur, Mut zu haben, denn Kraft ohne Vertrauen ist zu nichts nütze. Ich habe oft erlebt, daß mir durch einen unbedachten Schritt, der mich eigentlich an den Rand des Abgrunds hätte führen müssen, das Glück in den Schoß fiel. [...]

Trotz des Vorrates an trefflicher Moral als natürlicher Frucht der in meinem Herzen eingewurzelten göttlichen Prinzipien, bin ich ein Leben lang ein Opfer meiner Sinne gewesen. Vom rechten Weg abzuweichen, machte mir Vergnügen, und ich habe fortwährend Fehler begangen [...]. Aus diesem Grunde hoffe ich, lieber Leser, daß du, weit davon entfernt, in meiner Geschichte schamlose Prahlerei zu entdecken, darin solche Züge findest, die einer Generalbeichte zustehen, obschon du im Stil meiner Berichte weder das Gehabe eines Büßers noch das Schuldgefühl eines Menschen finden wirst, der errötend über seine losen Streiche Rechenschaft ablegt. ${ }^{6}$

In dieser etwas längeren Passage gibt es eine ganze Reihe von Charakteristika, die wir in der Folge immer wieder in Casanovas Reisebericht antreffen werden. Zum einen findet man am Anfang und am Ende der hier aufgeführten Überlegungen Casanovas direkte Anreden an den Leser, der nicht notwendig nur ein männlicher sein musste. Denn wir wissen heute, dass die erotische Literatur im 18. Jahrhundert gerade auch von Frauen - Marie-Antoinette ist hier nur ein besonders bekanntes Beispiel - sehr goutiert und gerne gelesen wurde.

Es scheint sich auf diese textinterne Weise eine direkte Beziehung zu bilden zwischen dem realen Autor und dem Ich-Erzähler einerseits - die gemäß des autobiographischen Pakts stillschweigend miteinander identifiziert werden - und einer expliziten (und allen impliziten) Leserfigur(en) andererseits. Dabei muß man dieser expliziten Leserfigur laut Ich-Erzähler (und hier besonders dem erzählenden Ich) ein gewisses Alter und eine gewisse Lebenserfahrung zuschreiben: Denn für die Jugend habe er fürwahr nicht geschrieben. Nun, ich werde dennoch Ihnen gegenüber keine größeren Vorsichtsmaßnahmen walten lassen.

Schließlich befinden wir uns laut Vorwort eindeutig auf dem Gebiet der Philosophie, auch wenn Casanova ein System in seinen Lebens-Untersuchungen beim besten Willen nicht erkennen will. Vielmehr macht er den Fehler als ein grundlegendes Erkenntnisinstrument aus: Man könnte sagen, dass Casanova durch seine vielen von ihm begangenen Fehler zwar vielfältig gescheitert ist, aber zugleich auch dadurch gescheiter wurde. Zumindest aus der Position des weise gewordenen

6 Casanova, Giacomo: Geschichte meines Lebens, Bd. 1, Vorrede, S. $63 \mathrm{f}$. 
erzählenden Ich, das seine Memoiren auf Schloss Dux verfasst. Reisen und Schreiben stehen so bei ihm in einem Wechselverhältnis des Lernens, das sich über Jahrzehnte seines Lebens erstreckt und auch im Alter noch nicht zu Ende ist.

Daneben findet sich eine schon $\mathrm{zu}$ Beginn recht deutlich prononcierte $\mathrm{Ab}$ sicht, das Christentum und den christlichen Glauben mit der Libertinage, mit der Freizügigkeit in philosophischen wie in erotischen Dingen, in Einklang und Übereinstimmung zu bringen. Es handelt sich dabei um eine Vorstellung, die Casanova - der ja einst eine Tonsur besesssen hatte - immer wieder der Erwähnung wert ist. Den Anspruch auf ein gottgefälliges Leben hat auch der alte Casanova im Angesicht seines baldigen Todes bei weitem nicht aufgegeben.

Natürlich hat dies auch mit der Frage der Zensur und der Gepflogenheiten im 18. Jahrhundert zu tun. Aber Casanova plante offenkundig nicht - obwohl er dann doch noch wohl auf Druck seiner Freunde einen erfolglosen Versuch der Veröffentlichung unternahm -, seine Lebenserinnerungen noch vor seinem Ableben $\mathrm{zu}$ veröffentlichen. Wir können mithin eine intensive Inszenierung der Beziehung zwischen Autor und Leserschaft von Beginn an konstatieren. Sie wird sich durch den gesamten Text ziehen und deutet auf einen Schriftsteller, der sehr wohl die Grenzen zwischen der Memoirenliteratur und der modernen Autobiographie bewusst überschritt. Als ein Prahlhans wollte der Ich-Erzähler freilich in den Augen der geneigten Leserschaft nicht dastehen.

Darüber hinaus aber wird ebenfalls deutlich, dass es eine gewisse Grundhaltung gibt, die wir in einem ganz positiven Sinne als Fatalismus bezeichnen können, gibt der Ich-Erzähler doch freimütig an, dem Wind gefolgt zu sein, der gerade blies und der ihn an jeweils bestimmte Orte führte sowie an andere nicht. Außerdem macht er in diesem Zusammenhang auch auf seine eigene Überwältigung aufmerksam: das Überwältigtsein von seinen Sinnen, denen er an entscheidenden Stellen seines Lebensberichts immer nachgegeben habe. Giacomo Casanova - ein Umhergetriebener von äußeren wie von inneren Beweggründen, ganz seinem eigenen Schicksal und keinem philosophischen System vertrauend?

Mit den deutlich fatalistisch eingefärbten Beweg-Gründen ist eine Aussage über die Wege und Wegerichtungen getroffen, wie wir sie im Romananfang von Denis Diderots Jacques le fataliste et son maître antreffen können und geradezu idealtypisch vorgebildet finden. Sie erinnern sich an das berühmte incipit dieses großen französischen Romans:

Wie hatten sie sich getroffen? Durch Zufall, wie jedermann. Wie nannten sie sich? Was kümmert sie das? Woher kamen sie? Vom nächstgelegenen Ort. Wohin gingen sie? Weiß man denn, wohin man geht?

Man könnte hier sehr wohl eine Verbindung zu Denis Diderots Text, mehr aber noch zu bestimmten Grundstrukturen herstellen, die wir gerade mit Blick auf die reiseliterarischen Orte im ersten wie im zweiten Teil unserer Vorlesung 
bereits näher untersucht haben. So zeigt sich hier auch als hermeneutische Bewegungsfigur ein gewisser Reiseverlauf, der eben vom Zufall geprägt ist und keinem System, keiner Methode (die etymologisch für den Weg steht) folgt, ja nicht einmal ein bestimmtes Ziel anvisiert. Damit sind die Beziehungen auch zum modernen Roman in der Nachfolge von Miguel de Cervantes' Don Quijote durchaus gegeben: Wir sehen, wie auch an dieser Stelle die Modernität von Casanovas Schreibrezept aufscheint.

Wir finden auf der Ebene der hermeneutischen Figuren bei aller Ziellosigkeit unseres Ich-Erzählers vielleicht eine gewisse Orientierung an Venedig, jener Stadt, an der sich Casanova in der Tat orientierte, so dass man zumindest in Teilen von einem sternförmigen Bewegungsmuster sprechen könnte. Aber bei genauerem Hinsehen müssen wir uns doch eingestehen, dass es kein eigentliches Grundmuster gibt, sondern dass wir es mit diskontinuierlichen, sprunghaften Reisebewegungen $\mathrm{zu}$ tun haben, denen unser männlicher Protagonist folgt. Denn es macht keinen Sinn, ein Grundmuster eben dort erkennen zu wollen, wo explizit ein solches unterlaufen wird und vor allem die Texte selbst immer wieder von Sprüngen und Diskontinuitäten geprägt sind.

Giacomo Casanovas Histoire de ma vie wäre damit ein gutes Beispiel für jenes Bewegungsmuster, das wir zwar im Reisebericht des 20. Jahrhunderts recht häufig finden, das im 18. jahrhundert aber eher selten ist. Casanovas Memoiren teilen dieses Muster mit Diderots Roman; und das romaneske Element ist zweifellos in den Memoiren dieses Venezianers mehr als genügend vorhanden. Denn von hier aus lassen sich auch Parallelen zum spanischen Schelmenroman, zur novela picaresca des 17. Jahrhunderts, ziehen.

Diese Verwandtschaften, Parallelen und Affinitäten mögen nicht zuletzt auch darin begründet liegen, dass es keineswegs Casanovas Absicht war, einen Reisebericht zu verfassen. Entscheidend aber ist für unsere Argumentation, dass er von Beginn der Histoire de ma vie an die Wegemetaphorik in seinen Text einblendet und zugleich selbstreferentiell auf seinen eigenen Text bezieht. Auf diese Weise haben wir es also mit Irrwegen und verschiedenen Pfaden, die sich verzweigen, mit einem Hin- und Her-Getriebenwerden von den jeweiligen Ereignissen und einem beständigen Abweichen vom 'rechten Wege' - der stets jener der Tugend ist - zu tun. Selbst die Reisen sind des Öfteren nicht freiwilliger Natur: Einkerkerungen, Ausbruchsversuche, Ausweisungen und fluchtartiges Verlassen sind narrative Elemente, die sich in diesem Leben als Reise, in diesem Lebensbericht als Reisebericht ständig wiederholen.

Giacomo Casanovas Lebensgeschichte ist folglich unstet und diskontinuierlich. Sie ist eine lange Beichte, aber vorgetragen in einem stolzen, selbstbewussten Ton - niemals in dem eines Büßers, der zutiefst sein Leben bereut hätte. Sie trägt damit auch auf dieser Ebene jene Züge des Schelmenromans, 
jener novela picaresca, von der wir bereits gesprochen haben. Und wie beim pícaro finden wir auch bei Casanova ein beständiges Queren unterschiedlichster sozialer Stände und Gruppen von den niedersten Klassen - also etwa den Bauern, zu denen auch die hübschen Bauernmädchen gehörten, die Casanova keineswegs verachtete - bis hinauf zu den höchstn Höhen der Gesellschaft, zu den Fürsten und vor allem Fürstinnen, Herzögen und Herzoginnen, an den großen europäischen Höfen.

Der eigentliche Treibstoff für seine Reisen aber ist das Begehren, wohl weitaus mehr noch als die Lust oder gar die Wollust, die er sich von seinen jeweiligen Eskapaden und Abenteuern erhofft. Giacomo Casanova ist einer, der sich zumindest nach Aussage seines Ich-Erzählers - treiben lässt im Vektorenfeld des Begehrens. In ihm ist ein unmäßiges Begehren, ständig neue Umgebungen, ständig neue Geliebte, ständig neue Erfahrungen und Erlebnisse zu sammeln.

Dabei sind seine erotischen Besitzergreifungen und heterosexuellen Inbesitznahmen ebenso wie sein ausgeprägtes Nomadentum von erstaunlicher Haltbarkeit und Widerstandsfähigkeit. Erst spät stellen sich bei ihm auf den verschiedensten Ebenen Ermüdungserscheinungen ein, wobei in der Forschungsliteratur, aber auch schon bei Casanova selbst das Jahr 1763 - und damit sein Aufenthalt in London - als ein Jahr der Wende dargestellt wird. Mag sein, dass ihn eine unerfüllte Liebe zu einem jungen, kaum achtzehnjährigen Mädchen fast in den Selbstmord und damit an einen Punkt stärkster Selbstreflexion führte. Casanova musste sich der Vektoren seines Begehrens wieder von neuem versichern.

Dass der Treibstoff der Reisebewegungen im Grunde immer ein Triebstoff war, macht Casanova mit seinem Verweis auf die sinnliche Dominanz seiner Lebenserfahrungen deutlich. Dieser sinnliche und zugleich sensualistische Aspekt seiner Lebensphilosophie ist vielfach gedeutet worden. Entsprechend stark ist auf dieser Bedeutungsebene auch die sinnliche Wahrnehmungswelt des Textes ausgestattet, betont der weitgereiste Venezianer doch schon in der Vorrede seines Werkes, dass jede Frau, in die er sich verliebte, stets für ihn angenehm duftete; und dass er dies um so mehr genoss, je mehr sie bei seinen zärtlichen Bemühungen ins Schwitzen kam. Gerade dieser olfaktorischen und taktilen Sinnenfreude dürfen wir bei der Analyse seines Lebensberichtes eine größere Aufmerksamkeit schenken, kommt ihr doch eine gleichsam dionysische Qualität zu.

Im Grunde ist der Lebensbericht also ein Reisebericht und der Reisebericht ein Liebesbericht aus dem Vektorenfeld eines unendlich wiederholten und erneuerten Begehrens. Die Bewegungen im Text und im Leben überlagern sich, die Mobilität schreibt sich ein in ein immer komplexer werdendes Vektorenfeld, das vom eigenen Begehren unter Spannung gehalten wird. Das Leben selbst 
erscheint als Reise, ein Topos, den wir seit der Antike in der abendländischen Literatur verfolgen können.

Wie aber ist dieser Text einzuordnen? wie also können wir ihn auf der Ebene der sechsten Dimension, der Beziehungen also zwischen Imagination und Realität, zwischen Fiktion und Diktion situieren? Giacomo Casanova gibt auch hierzu in seiner Vorrede klare Hinweise. Die nachfolgenden Reflexionen zeugen vom hohen Grad an Bewusstheit und Selbstreflexion bei dem galanten Philosophen:

Ein antiker Autor belehrt mich in schulmeisterlichem Ton: 'Wenn du nichts vollbracht, was das Aufschreiben lohnt, so schreibe wenigstens etwas, das wert ist, gelesen zu werden.' Diese Vorschrift ist so schön wie ein in England geschliffener Diamant reinsten Wassers, aber sie betrifft mich nicht, weil ich weder die Geschichte eines berühmten Mannes noch einen Roman schreibe. Ob wert oder unwert, mein Leben ist mein Stoff, und mein Stoff ist mein Leben. Da ich es gelebt habe, ohne je daran zu denken, mich könnte einmal die Lust packen, es aufzuzeichnen, mag es ein gewisses Interesse besitzen; das aber hätte es wohl kaum, wenn ich mein Leben in der Absicht geführt hätte, es in meinen alten Tagen niederzuschreiben und, was weit mehr ist, es auch noch zu veröffentlichen. ${ }^{7}$

Dieser Passage, die mit einem Zitat von Plinius dem Jüngeren beginnt und mit einem ironischen Verweis auf die keineswegs berühmte englische Diamantenschleifkunst weitergeht, wird danach von einer Datierung des Vorwortes explizit auf das Jahr 1797 fortgeführt, in welchem Casanova den bereits erwähnten Genuss bei der Niederschrift hervorhebt. In dem obigen Zitat aber geht es vor allem um die Frage der Legitimation der Niederschrift als solcher, denn eigentlich waren es nur die berühmten Männer, die dazu berechtigt waren, ihre Memoiren niederzuschreiben, die dann auch keineswegs Lebensberichte, sondern eher die Aufzeichnung von Erinnerungen an Treffen betrafen, die sie mit anderen berühmten Männern - und seltener auch Frauen zusammenführten. Was aber berechtigt einen Casanova, sein von ihm nie unter der Maßgabe einer späteren Verschriftlichung geführtes Leben darzustellen und dem von ihm beschriebenen Figuren Gewicht und Bedeutung zu geben? Was gab ihm das Recht, vom eigenen Leben nicht in Form eines Romans, sondern in der Gestalt von Memoiren zu berichten und zu erzählen?

Die unbestreitbare Tatsache, dass Casanova, der sich keineswegs zu den damals berühmten Männern zählen durfte, nur wenig Federlesens mit derlei Hemmnissen macht, die sein Schreiben verunmöglicht hätten, mag darauf verweisen, dass autobiographische Schreibformen im Gefolge von Rousseaus Confessions längst zu einer verbreiteten Äußerungsform gerade auch bei Menschen geworden waren, die keinerlei Berühmtheit unter ihren Zeitgenossen

7 Casanova, Giacomo: Geschichte meines Lebens, Bd. 1, Vorrede, S. $66 \mathrm{f}$. 
erlangt hatten. Wir wissen heute von vielen einfachen, aber des Schreibens kundigen Menschen, die autobiographische Schreibformen im ausgehenden 18. Jahrhundert praktizierten und weiterentwickelten. Es gab folglich ein offenkundiges Begehren, sich selbst in seiner eigenen Unwiederholbarkeit literarisch darzustellen.

Für Casanova aber liegt die gesamte Begründung seines Schreibens nicht in jenen gekrönten und ungekrönten Häuptern, die er in seiner Lebensgeschichte Revue passieren lassen kann - und es sind deren viele, von denen nicht wenige es vorgezogen hätten, im schweigsamen Schatten zu bleiben -, sondern in seinem eigenen Leben, seinem Leben selbst: Denn „mein Leben ist mein Stoff, und mein Stoff ist mein Leben.“ Im Zentrum steht also dieses einzigartige Leben in seinen Irrwegen, in seinen ständig unruhig-diskontinuierlichen Bewegungen, Einkerkerungen, Fluchtversuchen, Ausbürgerungen, Verbannungen, in seinem Nomadisieren und seiner immer wieder reüssierenden Sinnlichkeit, die ihm nicht nur die Herzen der Frauen zufliegen ließ. Denn Casanova schreibt wie einst Rousseau ein Leben, wie es keines vor ihm gab und keines nach ihm geben sollte. Das moi seul von Jean-Jacques gilt auch für Giacomo.

Aus unserer in dieser Vorlesung gewählten Perspektive ist aber wichtig zu konstatieren, dass wir es laut Casanovas Vorwort weder mit der Geschichte eines berühmten Mannes - also einer Biographie - noch mit einem Roman - in seiner romanesken Form - zu tun haben. Es geht damit weder um Diktion noch um Fiktion im Sinne Gérard Genettes, sondern ganz deutlich um Friktion: um eine Friktionalität, wie sie auch und gerade für den literarischen Reisebericht charakteristisch ist.

Aufschlussreich ist es, die Rezeptions- und Wirkungsgeschichte - auf die ich an dieser Stelle nicht ausführlich eingehen kann, obwohl hier editionsgeschichtliche wie auch zensurgeschichtliche Aspekte von großer Wichtigkeit sind - hierzu zu befragen. In ihrem bisherigen Verlauf fällt auf, dass Casanovas Geschichte meines Lebens insbesondere im 19. Jahrhundert als weitgehend frei erfunden dargestellt wurde: Man glaubte dem Venezianer nicht so leicht und hielt viele seiner Anekdoten für erlogen. Nicht wenige leugneten die Existenz Casanovas überhaupt, die ganze Geschichte wurde als literarische Erfindung verbucht. Dies war ein Schicksal, das auch seinem großen Landsmann Marco Polo über lange Zeit widerfahren war, schrieb man seinem Reisebericht, der nicht umsonst als Il Milione tituliert wurde, doch eine ungeheure Vielzahl an Lügen und Erfindungen zu. Doch man täuschte sich ebenso in Marco Polo wie in Giacomo Casanova.

Casanova wies in seinem Vorwort ja selbst darauf hin, dass es ihm weder um eine Liebesprahlerei noch um eine verheulte Lebensbeichte gehe. Man darf wohl sagen, dass er wie Jean-Jacques selbstbewusst mit dem Buch seines 
Lebens in der Hand vor den Schöpfer treten wollte. Und so haben die Forschungen insbesondere im 20. Jahrhundert eindrucksvoll dokumentiert, wie präzise die Erinnerungen und die Gedächtnisleistung des Venezianers sind, wie genau er sich - selbstverständlich unterstützt von seinem Tagebuch - an bestimmte Abläufe erinnert, auch wenn sich bisweilen Fehler und Lücken in seiner narratio nachweisen lassen. Aber dies ist bei einem Abstand von mehreren Jahrzehnten wahrlich keine Überraschung.

Damit setzte übrigens auch gleich eine Legendenbildung um den großen zum Verführer stilisierten Venezianer ein, der zum ersten Mal durch seine spektakuläre Flucht aus den Bleikammern Venedigs - die er nachträglich 1788 beschrieben und separat in Buchform veröffentlichte, später aber in veränderter Form in seine Memoiren miteinbezogen hat - bei einer europäischen Öffentlichkeit auf sich aufmerksam machte. Casanova war folglich durchaus ein Gedächtniskünstler, dem es um eine möglichst präzise Darstellung seiner Lebens- und Liebesabenteuer ging. Daraus aber nun den wie in einem Pendelschlag umgekehrten Schluss zu ziehen, es handele sich bei den Mémoires de ma vie ganz einfach um einen dokumentarischen Text, der sich in einen direkten Bezug zur außersprachlichen Wirklichkeit setzen lasse, halte ich meinerseits wiederum für eine Verabsolutierung einer dokumentarischen, diktionalen Lektüre, die der Komplexität der Memoiren Casanovas nicht gerecht wird.

Kein Zweifel kann daran bestehen, dass Casanova, der übrigens im Alter neben vielen anderen Schriften noch einen utopischen Roman verfasste, sich selbst als philosophe, als honnête homme und vor allem als homme de lettres verstand. Er sah sich in der République des Lettres als einen Schriftsteller, der zwar als italienischer Muttersprachler im Französischen mit mancherlei Tücken und fehlgeleiteten Italianismen zu kämpfen habe, aber gleichwohl über ein hohes Talent als Literat von europäischem Format verfügte. Und soviel darf ich an dieser Stelle schon verraten: Er ist tatsächlich ein talentreicher und durchaus versierter Autor.

Halten wir also fest: Schon bei dieser Lebensgeschichte als Reisebericht (oder umgekehrt) können wir von einer klaren friktionalen Grundstruktur der Mémoires de ma vie ausgehen, welche insoweit spannend ist, als gerade die vielen referentialisierbaren Bezüge zur außersprachlichen Wirklichkeit Casanova die Möglichkeit eröffnen, gleichsam wie in einem historischen Roman die einzelnen Szenen nur um so präziser und absichtsvoller $\mathrm{zu}$ inszenieren und $\mathrm{zu}$ arrangieren. Leider können wir anhand der Tagebücher derlei 'Abweichungen' im Sinne von Inszenierungen nicht mehr nachweisen: Casanova dürfte sie wie auch alle anderen Dokumente, die er Zeit seines Lebens zusammengetragen hatte, im hohen Alter auf Schloß Dux vernichtet haben. 
Ein Wort noch zur gattungsspezifischen Komplexität von Casanovas Histoire de ma vie. Dieser Text steht der Memoirenliteratur recht nahe, mit der er gemein hat, dass die Erinnerung an vergangene Zeiten im Mittelpunkt steht. Doch treibt ihn anders als die Gattung der Memoiren nicht die Begegnung mit bekannten und renommierten Persönlichkeiten voran, sind die Frauen, denen Casanova begegnete, doch zwar oft hoher Abkunft, aber nicht unbedingt als große Persönlichkeiten einzustufen, denen sich Memoiren widmen würden. Die Histoire de ma vie hat daher etliche Verbindungspunkte mit der im 18. Jahrhundert entstandenen neuen Gattung der modernen Autobiographie, welche die Darstellung der Entwicklung eines Ich, das mit keinem anderen vergleichbar ist, als Ziel besitzt. Dabei erfolgt traditionellerweise eine Trennung dieses Ich in ein erzählendes und ein erzähltes Ich, deren zeitliche distanz im weiteren Fortgang des Erzählens schwindet, bis sie möglicherweise gegen ende ganz gering oder gleich Null tendiert.

Dies wiederum verbindet die Autobiographie mit dem Reisebericht, der ebenfalls diese Auftrennung kennt und die Differenz zwischen dem gereisten und dem reisenden Ich in der klassischen Variante als gattungsspezifisches Wasserzeichen besitzt. An eben dieser Stelle aber setzt nun die Relation mit der novela picaresca ein, mit dem klassischen Schelmenroman, der ebenfalls ein Ich ins Zentrum stellt, das ganz wie Casanova von der einen in die nächste Situation verschlagen wird und dabei die sozialen Kontexte der jeweils beleuchteten Figuren relativ stark ausarbeitet. So bewegt sich der Text von Casanova in ständiger Bewegung zwischen diesen vier Gattungen hin und her, wobei die friktionale Dimension dieser Gattungsbewegungen unverkennbar ist.

Und noch ein zweites Wort zur Reise und ihrem Verhältnis zum Schreiben. Denn im Kontext des Libertinage gibt es im Grunde zwei Darstellungsweisen mit Blick auf die räumliche Bewegung in der Schilderung von Liebesabenteuern. Zum einen haben wir dabei das Modell des Marquis de Sade, der in seiner Literatur hauptsächlich an den Bewegungen der Körper interessiert ist und Körpertechniken beleuchtet, die an ein und demselben Ort ausgeführt und über lange Tage quasi-experimentell analysiert werden. Die zweite Variante verkörpert zum anderen Casanova, indem eine unbestimmte Folge von Liebesbegegnungen nicht an einem einzigen oder sehr wenigen Orten, sondern in einer ebenso offenen Sequenz von Lokalitäten durchgeführt werden, so dass sich im Sinne von Casanova durch die Liebschaften und Liebesabenteuer ein wahrer Reisebericht ergibt. Bei diesen Reiseberichten kommen nicht nur den Körpern, sondern den sozialen, ökonomischen, kulturellen oder politischen Kontextualisierungen eine erhebliche Bedeutung zu, welche die Histoire de ma vie wiederum mit dem Schelmenroman verbindet. 
Wir sollten uns in der Folge nun einige Passagen aus dem eigentlichen Reisebericht näher anschauen, die aus der Perspektive unserer Vorlesung von Interesse sind. Dabei werden wir uns freilich mit einigen wenigen repräsentativen Geschichten aus seinem Leben begnügen müssen: $\mathrm{Zu}$ umfangreich ist sein Oeuvre, als daß wir uns damit exhaustiv beschäftigen könnten.

Natürlich ist es für uns Brandenburger nebst Zugereisten stets interessant, ob auch unser schönes Potsdam in einem Reisebericht des 18. Jahrhunderts vorkommt. Ja, eben dies ist schon bei Casanova der Fall. Ich hatte schon erwähnt, dass seine Erfahrungen 1763 in London - insbesondere mit einer ihm nicht gefügigen jungen Dame - nicht die besten waren, so dass er später dieses jahr 1763 als einen Wendepunkt in seinem Leben ansah. Er verließ schließlich im März 1764 überstürzt die englische Hauptstadt, um zurück auf den Kontinent zu kommen, wo er über Dünkirchen, Brüssel, Lüttich, Wesel, Minden und Braunschweig, wo er sich in der Nähe gleich die wunderbare Bibliothek zu Wolfenbüttel zeigen ließ, Magdeburg erreichte. Von dort wiederum brach er nach Berlin auf und machte selbstverständlich auch in Potsdam am Hofe zu Sanssouci Station. Dort wollen wir ihn neugierig empfangen.

Kein Geringerer als Friedrich der Große hat ihn nach eigenem Bekunden als einen schönen Mann empfunden, auch wenn die Begegnung zwischen beiden nicht besonders intensiv und lange währte. Giacomo Casanova kam im Juli nach Potsdam und Berlin; im August besuchte er gemeinsam mit Friedrich dem Großen eine Kadettenanstalt, was der preußische König dazu nutzte, seinem venezianischen Gast das Angebot zu unterbreiten, an dieser Kadettenanstalt als Erzieher zu arbeiten. Sie mögen daran erkennen, wie gut noch immer Casanovas Ruf war - oder wie wenig sich der preußische König um diesen Ruf einen Kopf machte.

Jedenfalls war dieser Ruf ein gänzlich anderer als jener, der ihm seit dem 19. Jahrhundert vorauseilte. Giacomo Casanova, der Chevalier de Seingalt, jedenfalls lehnte dankend ab, was wir herzlich bedauern: Denn wir hätten seine pädagogischen und didaktischen Schritte mit den ihm anvertrauten jungen Kadetten gerne in Erzählungen und Dokumenten der Zeit nachvollzogen.

So aber reiste der weltgewandte Venezianer im September 1764 wieder ab und ging über Danzig und Königsberg nach Mitau, um die Zeit von Oktober bis Dezember 1764 in Riga zu verbringen, bevor er Ende Dezember in Sankt Petersburg am Hofe von Katharina II. eintraf. Das Jahr 1765 verbrachte er zunächst in Sankt Petersburg; im Mai machte er einen Ausflug nach Moskau. Doch seine Hoffnungen auf eine Stelle am russischen Hof erfüllten sich nicht. Die Weiterreise nach Warschau und das sich anschließende Duell hatte ich bereits erwähnt. Sie sehen: unaufhörliche Reisebewegungen eines Stadt-Nomaden aus Venedig. Was aber geschah genau in Potsdam? 
Nun, um Sie gleich zu enttäuschen: Es ist keine Liebesgeschichte, keine der zahlreichen Affären, die Casanova sonst so leidenschaftlich anzettelte, aus dieser Zeit überliefert. Die Potsdamer Schönheiten scheinen auf Casanova ihre Wirkung nicht entfaltet zu haben. Aber hübsche Anekdoten gibt es dennoch, und ich möchte sie Ihnen auch keineswegs vorenthalten. Wo konnte Casanova in Potsdam den König der Preußen erblicken? Natürlich wie immer, bei der Parade, wo sonst?

In Potsdam sahen wir den König bei der Parade; er kommandierte sein erstes Bataillon, dessen Soldaten alle in den Uhrtäschchen ihrer Hosen eine goldene Uhr hatten. So belohnte der König den Mut, den sie bewiesen hatten, als sie ihn unters Joch nahmen, wie einst Cäsar in Bithynien den Nikomedes. Man machte gar kein Hehl daraus.

Unser Schlafzimmer im Gasthof lag gegenüber einem Durchgang, den der König benutzte, wenn er das Schloß verließ. Die Läden der Fenster waren geschlossen; unsere Wirtin erzählte uns den Grund. In dem gleichen Zimmer wie wir hatte nämlich die sehr hübsche Tänzerin Reggiana gewohnt, und als der König sie eines Morgens beim Vorübergehen ganz nackt erblickt hatte, war sogleich der Befehl ergangen, daß man die Fenster schließen solle; das war schon vor vier Jahren geschehen, doch hatte man sie nie wieder geöffnet. Seine Majestät hatte vor ihren Reizen Angst gehabt; nach seiner Liebschaft mit der Barberina wollte er nichts mehr davon wissen. Später sahen wir im Schlafzimmer des Königs das Porträt dieses Mädchens, das der Cochois, der Schwester der Schauspielerin, die den Marquis d'Argens geheiratet hatte, und das der Kaiserin Maria Theresia aus ihrer Jungmädchenzeit, in die er sich verliebt hatte, weil er Kaiser werden wollte.

Nachdem wir die Schönheit und die Eleganz der Räume des Schlosses bewundert hatten, sahen wir überrascht, wie er selbst wohnte. Wir erblickten in einer Ecke des Zimmers hinter einem Wandschirm ein schmales Bett; Hausrock und Pantoffel waren nicht vorhanden. Der anwesende Diener zeigte uns eine Nachtmütze, die der König aufsetzte, wenn er erkältet war; sonst behielt er seinen Hut auf, was recht unbequem sein mußte. ${ }^{8}$

Sie sehen: Wir erfahren bei dieser Art von Hofberichterstattung eine Menge Klatsch und Tratsch, was sicherlich auch durchaus zeitgemäß war in der gesellschaftlichen Elite des 18. Jahrhunderts. Schon damals gab es jede Menge Paperazzi, die aus erster Hand möglichst getreue Portraits des Lebens der Monarchen schießen wollten. Der König von Preußen schlief also mit Hut und hatte keine Pantöffelchen.

Aber wir sehen zugleich, wie präzise Casanova beobachtet und darüber hinaus basierend auf seinen Notizen noch Jahrzehnte später alles festhielt, was ihm erlauben konnte, eine bestimmte Gesellschaft oder eine bestimmte Persönlichkeit - hier jene von Friedrich dem Großen - zu porträtieren. Dieses Portrait in Abwesenheit des Königs wird später noch durch mehrfache Beobachtungen in presentia ergänzt: Auch von einem Dialog wird berichtet, doch können wir dies getrost beiseite lassen - dies sind die sozialen Netzwerke, wie sie im 18. Jahrhundert funktionierten.

8 Casanova, Giacomo: Geschichte meines Lebens, Bd. 10, S. 87. 
Sie merken schon: Es geht Giacomo Casanova bei weitem nicht ausschließlich um die Darstellung der verschiedenen Abenteuer - und vor allem Liebesabenteuer -, die er quer durch Europa, von der Südspitze Italiens bis nach Moskau, von Preußen bis nach England, von Polen bis nach Spanien, nicht zuletzt aber in Frankreich und Italien erlebte. Es handelt sich dabei vielmehr um ein Bild, jenes des unwiderstehlichen Frauenverführers oder wie man heute sagen würde womanizers, welches die eher anthologischen Ausgaben gezeichnet und verstärkt haben. Liest man aber die Histoire de ma vie vorurteilslos, dann zeigt sich, dass selbst noch die Beschreibung der Frauenzimmer - wie bei der Darstellung dieses Frauenzimmers in Potsdam - den Blick nicht nur auf nackte Tatsachen, sondern auf soziale und kulturelle Situationen und Entzwicklungen eröffnet. Auf diesem Gebiet kann die Bedeutung der Memoiren Casanovas gar nicht unterschätzt werden: Sie vermitteln uns ein anschauliches Bild vom Leben einer gesellschaftlichen Elite im europäischen 18. Jahrhundert, auch wenn sie sich keineswegs auf das Dokumentarische beschränken.

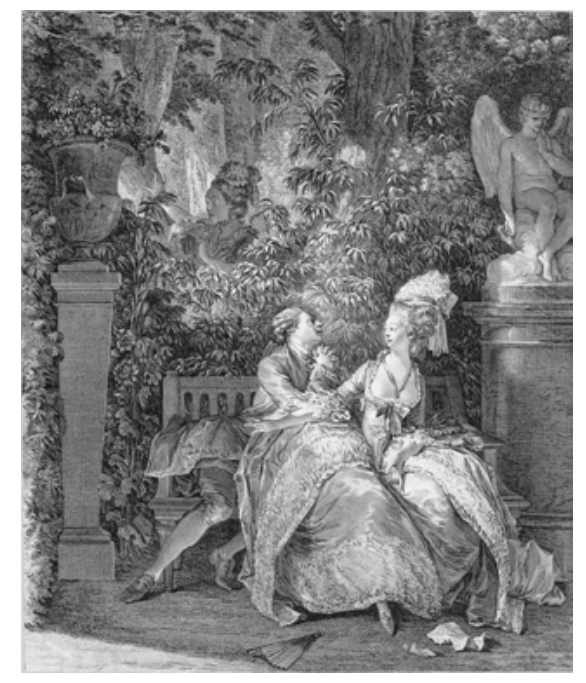

Abb. 55: „Oui ou non“, Radierung von JeanMichel Moreau le Jeune, 1781.

Ich habe bereits auf die große Fülle von Auswahlbearbeitungen hingewiesen, die reißenden Absatz fanden, weil sie den Hunger des Lesepublikums nach erotischer Literatur ein wenig zu stillen halfen. Diese Ausgaben haben im Grunde erst zu dem einseitigen Bild des Venezianers geführt, das uns aus dem 19. Jahrhundert überliefert wurde. Casanova war übrigens in seiner Darstellung gerade der erotischen Szenerien wesentlich präziser und klarer als seine späteren 
Bearbeiter, die gerne eine gewisse Schlüpfrigkeit herstellten. Auch in erotischen Dingen war Casanova also ebenso genau und zuverlässig wie in seiner Darstellung historischer Abläufe oder seinen Portraits europäischer Fürsten. Erich Loos hat zurecht auf eine geradezu verblüffende Zuverlässigkeit der Memoiren Casanovas und auf sein ungeheuer entwickeltes Erinnerungsvermögen hingewiesen. ${ }^{9}$ Casanova war auch bei der sorgsamen Überarbeitung seiner Memoiren äußerst umsichtig, deren erste Fassung er bereits 1793 abschloss. Er nahm sich seine Mémoires de ma vie aber bis zu seinem Tode im Jahre 1798 immer wieder vor und überarbeitete sie mit Hingabe.

Wie dereinst Jacques le fataliste et son maître veränderte Casanova immer wieder auf Grund von Zufallsbegegnungen seine Reiseroute. Kein Ziel war ein für alle Mal festgelegt. Er selbsts macht darauf aufmerksam, und wir können in dieser Vektorisierung des Begehrens durchaus eine Art von Vergeschlechtlichung der Reiseziele erkennen. Ich möchte Sie an dieser Stelle nur darauf aufmerksam machen und zugleich daran erinnern, dass uns schon das Rebecca-Motiv darauf hingewiesen hatte, wie sehr das Begehren nach der Erfahrung eines Landes bei männlichen Reisenden das Land selbst mit geschlechtlichen (in diesem Falle weiblichen) Attributen ausstattet. Auch die Geschlechterdiskurse des frühen Kolonialismus hatten uns auf diese Dimension, die wir als neunte Dimension untersucht hatten, aufmerksam gemacht. Der Reisebericht Giacomo Casanovas bildet auf dieser Ebene folglich keine Ausnahme.

Wir werden noch viele Beispiele dieser geschlechterspezifischen Differenzierung sehen. An dieser Stelle möchte ich Ihnen jedoch gerne eine Passage zeigen, die im Grunde den zweideutig-eindeutigen Ruf Casanovas begründete. Sie erlaubt freilich in ihrem gerafften Ablauf eine Reihe von Einblicken in die kulturellen, gesellschaftlichen und moralischen Kontexte der Zeit insoweit, als hier eine repräsentative Geschlechterbeziehung geknüpft und sexuell vollzogen wird.

Der Handlungshintergrund ist rasch erzählt. Der Ich-Erzähler hat gerade nicht nur das eigene Geld, sondern auch die Diamanten einer Geliebten verspielt und zugleich an den reichen Murray seine andere Geliebte, Tonina, abgetreten. Das Schicksal hält freilich nur wenige Zeilen später einen Trost für den Reisenden bereit, und zwar in Gestalt von Toninas jüngerer Schwester Barberina, die sich dem Venezianer ganz bewusst als jenem Manne nähert, der sie von der Jungfernschaft befreien soll.

Hier nun die kurze, gedrängte Szene. Barberina bittet überdies ihren Geliebten vor der Einwilligung, danach ihrer Schwester Tonina davon zu berichten und förmlich zu bestätigen, dass sie zuvor noch Jungfrau gewesen sei. Der Ich-Er-

9 Vgl. Loos, Erich: Einleitung, S. 37-60. 
zähler willigt leichten Herzens ein - und auch dies gewährt uns tiefe Einblicke in das zeitgenössische Verständnis von Sexualität:

Nach dieser Einleitung frühstückten wir; dann legten wir uns in vollkommenem Einverständnis ins Bett und hatten eher den Eindruck, Hymen zu opfern als Amor.

Das Fest war für Barberina neu, und ihre Wonnen, ihre unreifen Ideen, die sie mir mit der größten Naivität mitteilte, und ihre von reizender Unerfahrenheit gewürzte Hingabe überraschten mich, weil ich selbst alles neu fand. Ich glaubte, eine Frucht zu genießen, deren Süße ich in der Vergangenheit noch nie so vollkommen genossen hatte. Barberina schämte sich, mir einzugestehen, daß ich ihr weh getan hatte, und das gleiche Bedürfnis nach Verstellung spornte sie dazu an, mir in jeder Hinsicht zu beweisen, daß sie größere Lust empfand, als es wirklich der Fall war. Sie war noch kein ausgewachsenes Mädchen, und die Rosen ihres knospenden Busens waren noch nicht erblüht; voll entwickelt war sie nur in ihrem jungen Kopf.

Wir standen zum Mittagessen auf; dann legten wir uns erneut ins Bett und blieben darin bis zum Abend. Laura fand uns bei ihrer Rückkehr angezogen und zufrieden. Ich schenkte der hübschen Barberina zwanzig Zechinen und verließ sie mit dem Versprechen meiner ewigen Liebe, sicherlich ohne jede Absicht, sie zu täuschen; aber was das Schicksal für mich bereithielt, ließ sich schlecht mit solchen Plänen vereinen. ${ }^{10}$

Die Szenerie dieser Entjungferung wird mit einer im Grunde recht knappen, von topischen Metaphern nur vordergründig ausgeschmückten Sprache behandelt. Der Stil Casanovas ist an dieser Stelle nicht üppig, sondern zurückhaltend beschreibend, ebenso mögliche Reflexionen seiner Liebespartnerin wie auch eigene Überlegungen miteinbeziehend. Es ist ein männlicher Blick auf sein weibliches Gegenüber, doch wird versucht, beide Geschlechter gleichsam in einem Dialog darzustellen sowie in ihrem jeweiligen Erleben der ebenso erotischen wie technischen Szenerie.

Zunächst dürfen wir festhalten, dass es sich um Beischlaf mit Minderjährigen handelt, was freilich eine anachronistische Übertragung aktueller Gesetzlichkeit auf das 18. Jahrhundert darstellt. Wohl niemand wäre im Jahrhundert der Aufklärung auf eine solche juristisch geprägte Vorstellung gekommen. Festhalten dürfen wir auch, dass die Initiative für diesen Akt - wie so häufig bei Casanova - von der weiblichen Liebespartnerin ausgeht, die im Grunde die latente Bereitschaft des Venezianers abruft.

Diese ungleiche Rolle der Liebespartner, gepaart mit einer deutlich aktiveren Rolle der Frau, ist im Übrigen auch schon in seiner ersten zärtlichen Begegnung der Fall, jener jungen Bettina, der Schwester von Dottore Gozzi, wo der junge Casanova in Padua ins Internat ging. Wie diese Bettina ergreift auch Barberina die Initiative, und was dann abläuft, hat fast etwas Maschinenhaftes mit einem

10 Casanova, Giacomo: Geschichte meines Lebens, Bd. 4, S. 199. 
gewissen klinischen Blick an sich. Denn der Ich-Erzähler brüstet sich nicht etwa mit seinen Wunder- und Heldentaten, sondern hält den Schmerz und das Bemühen des Mädchens fest, sich der Situation gewachsen zu zeigen und Lust vorzutäuschen, wo eigentlich Schmerz vorherrscht.

In einem deutlichen Kontrast zu diesem Blick des Liebespartners stehen sowohl die Liebesschwüre des Ich-Erzählers, die freilich von dem anderen Ich, dem erzählenden Ich, gleichsam relativiert, in ihrer Authentizität bestätigt, gleichzeitig aber als nicht mit dem weiteren Lebensweg vereinbar definiert werden. Das männliche Ich kennt zu diesem Zeitpunkt bereits alle Mechanismen körperlicher Liebe und durchschaut als erfahrener Liebhaber zugleich auch die Stratageme der Frau, die in ihrem Kopf und nicht in ihrem Körper bereits entwickelt sind. Es ist möglich, dass sich auch hier eine Parallele zu Bettina zeigt: Denn auch die Barberina könnte wie ihre Vorgängerin in ihrem Kopf in Liebesdingen so weit entwickelt sein, weil sie schon soviel Literatur dazu gelesen hat. Auf dieses Thema der frühen erotischen Lektüren kommt Casanova in der $\mathrm{Ge}$ schichte meines Lebens im Übrigen mehrfach zurück.

Bemerkenswert ist in dieser Passage auch, in welchen Assoziationskontext, in welche Metaphorologie, das junge Mädchen gestellt wird. Denn sie erscheint als süße Frucht, die das männliche Ich genießt und sich einverleibt. Sie wird als Frau gleichsam naturalisiert, wird zu einem Stück Natur, das sich dem männlichen Blick und dem männlichen Biss hingebungsvoll darbietet. Ihre Hingabe wird dazu mit der Unerfahrenheit gewürzt, welche auch beim Ich-Erzähler deutlich neue Erfahrungshorizonte öffnet; denn er hat es längst ausschließlich mit sexuell sehr erfahrenen Frauen zu tun. Die junge Liebespartnerin wird aber zugleich in der Rede des Ich-Erzählers objektiviert und distanziert; und in diesen Kontext mag am Ende auch das Geld passen, das gleichsam als letzter Abschiedsgruß sowie als Entgelt für die kostenlosen Liebesschwüre gilt, denen doch keine Zukunft beschieden sein konnte.

Barberina verkörpert im besten Sinne den Typus des unschuldigen Mädchens, zugleich aber auch den Topos der Zufallsbekanntschaft, des von Beginn an erotisch aufgeladenen Treffens mit einer unbekannten Schönen an einem dem Reisenden unbekannten Ort. In dieser Konstellation liegt zum einen die Bedeutung einer Szenerie, die sich in den Reiseberichten unzähliger männlicher Autoren abendländischer Herkunft ein ums andere Mal präsentiert, wobei sich ebenso die Unbekannte wie auch das unbekannte Land in dieser gleichsam naiven Form dem Durchreisenden darbieten.

Zugleich wird auch ein literarisches Motiv erkennbar, das Charles Baudelaire in seinem berühmten Gedicht 'A une passante' auf die Großstadt und die zwar mögliche, aber niemals realisierte Liebe zwischen dem männlichen Ich und einer schönen Zufallsbegegnung verfasste. Hier freilich handelt es sich 
um das uns bereits bekannte Rebecca-Motiv, das nun aber in Gestalt einer völligen Selbstverständlichkeit der Hingabe im Angesicht des männlichen Blickes in Szene gesetzt wird. Giacomo Casanova spielt mit den literarisch tradierten Motiven, wählt aus einem reichen Fundus an Topoi aus, um seine (Liebes-)Geschichten und Anekdoten in dieser literarisch bearbeiteten Einkleidung erscheinen zu lassen. Und er erweist sich bei dieser Arbeit als ein höchst geschickter literarischer Autor.

Dabei ist nicht immer deutlich, wem die Verstellung gilt: Ist sie Täuschung des Fremden, des Mannes, die dieser doch durchschaut? Oder ist sie der vielleicht tapfere, vielleicht verzweifelte Versuch, aus der Rolle des weiblichen Opfers auszubrechen, in welche die Geschlechterkonstellation die Barberina getrieben hat? Dann hätten wir es hier gleichsam mit einem weiblichen Gegenstück des aktiven Fatalismus zu tun, für den sich Casanova und seine Ich-Erz ählerfigur auszusprechen scheinen, ein Fatalismus freilich, der sich der beschränkten Möglichkeiten seiner Wirkung und seiner Lebenschancen durchaus bewusst wäre. In jedem Falle spielt das Moment der Verstellung, der Verkleidung, der (vor allem literarisch bestimmten) Travestie eine wichtige Rolle in den Erzählungen Giacomo Casanovas.

Wir können jedenfalls konstatieren, dass die Barberina den Reisenden nicht halten kann: Sie kann ihn nur zu einem längeren Aufenthalt an einem bestimmten Ort verführen. Auch dies scheint mir charakteristisch für den abendländischen Reisebericht zu sein, denn das Reise- und Wandermotiv darf nicht aufgegeben werden, würde doch sonst die gesamte Bewegung im Erzähltext zum Stillstand kommen. Dies aber wäre das Ende der Reise und des Reiseberichts.

An eben dieser Stelle ergibt sich auch eine Beziehung zum Sammeln, zum Kollektionismus. Denn der Sammler ist nie an einem wirklichen Endpunkt angekommen: Es fehlen ihm stets immer noch andere Stücke, ist eine Sammlung doch im Grunde niemals wirklich komplett, niemals vollständig und abgeschlossen. Der Kollektionismus Casanovas aber ist der Kollektionismus des Reisenden, der die Stücke nicht an sich, sondern in ihren Relationen benötigt, in ihren und seinen Verhältnissen, die ein Muster erzeugen, in welchem er sich selbst wiederfindet oder doch wiederfinden kann. Dies wäre eine wirkliche $R e$ lation historique, also ganz die gattungstypische Bezeichnung für den Reisebericht im 18. und zu Beginn des 19. Jahrhunderts.

Lassen Sie uns am Ende unserer Beschäftigung mit Giacomo Casanova noch einmal an den Ausgangspunkt der Histoire de ma vie, in die Kindheit des Protagonisten also, zurückkehren. Denn auf den ersten Seiten dieses Lebensberichts Casanovas zeichnen sich bereits jene Grundstrukturen ab, die den gesamten weiteren Lebensweg des Ich durchziehen werden. Dies konnte das erzählte Ich natürlich nicht wissen, das erzählende Ich freilich sehr wohl. Die ständigen Überarbeitungen 
des Reiseberichts vermitteln diesem eine zusammenhängende Struktur, innerhalb derer bestimmte Rekurrenzen gleichsam als basso continuo durchlaufen und dem Reise- und Liebesbericht durchaus zeittypisch eine gewisse heitere Musikalität vermitteln.

Wie in der Figur der Bettina bereits viele weitere weibliche Figuren, darunter auch Frauenfiguren mit mancherlei schmerzlichen Erlebnissen und Erfahrungen, enthalten sind, so lassen sich auch auf dem Gebiet der Reise grundlegende Strukturen - wie etwa das Grundmuster des Intermezzo mit einer aktiven, initiativ werdenden Frau - bereits sehr früh erkennen. Die Szene, die ich Ihnen in diesem Zusammenhang abschließend gerne vorstellen möchte, hat dabei auf den ersten Blick viel Belangloses. Doch sehen wir sie uns etwas näher an.

Es handelt sich um die erste Reise des Ich-Erzählers im gesamten Text; und sie ist sehr erkenntnisreich. Nicht etwa mit einer Geliebten, sondern mit der Mutter von Venedig nach Padua an Bord eines Schiffes, des Burchiello, das mitten in der Nacht seine Reise beginnt. Das Ziel der Reise wird angesteuert, weil die Ärzte empfohlen haben, den Jungen von Venedig zu entfernen, da das dortige Klima an seinen starken Nasenblutungen schuld sei - ein Leiden, das Casanova im Verlauf seines langen Lebens übrigens niemals wirklich besiegen konnte. Wolle man den Jungen nicht verlieren, so hieß es, dann müsse man ihn in ein anderes Klima bringen. Also Padua, wo der Junge bei einer Frau in die Obhut gegeben werden soll, die ihn dann zur Schule schicken und über ihn wachen soll. Interessant ist nun, wie die Reise dargestellt und fokalisiert wird und inwieweit sie gleichsam eine mise en abyme vieler anderer, nachfolgender Reisen darstellt:

Sobald es tagte, stand meine Mutter auf und öffnete ein Fenster gegenüber meinem Bett. Die Strahlen der aufgehenden Sonne trafen mein Gesicht und ließen mich die Augen aufschlagen. Das Bett war so niedrig, daß ich das Land nicht sehen konnte. Ich erblickte durch das Fenster nur die Wipfel der Bäume, mit denen die Ufer des Flusses durchweg gesäumt sind. Das Schiff schwamm dahin, doch mit einer so gleichmäßigen Bewegung, daß ich davon nichts spüren konnte. Deshalb setzten mich die Bäume, die rasch vor meinen Augen vorbeizogen, in Erstaunen. 'Ach, liebe Mutter!' rief ich. 'Was ist denn los? Die Bäume wandern ja!'

In diesem Augenblick kamen die beiden Herren herein, und als sie mich so verdutzt sahen, fragten sie, was mich denn so beschäftige. 'Wie kommt es', fragte ich zurück, 'daß die Bäume wandern?'

Sie lachten; meine Mutter aber seufzte und sagte mitleidig zu mir: 'Das Schiff bewegt sich und nicht die Bäume. Zieh dich jetzt an.'

Ich begriff augenblicklich, wie diese Erscheinung zustande kam, und mit meinem erwachenden und ganz unvoreingenommenen Verstand dachte ich folgerichtig weiter. 'Dann ist es also möglich', sagte ich zu ihr, 'daß sich auch die Sonne nicht bewegt, sondern daß wir es sind, die von Westen nach Osten wandern.' Meine gute Mutter jammerte über so viel Dummheit, und Signor Grimani beklagte meinen Unverstand; ich stand ganz verstört und traurig da und war dem Weinen nahe. Nur Signor Baffo gab mir wieder neuen Mut. Er kam auf mich zu, küßte mich zärtlich und sagte: 'Du hast recht, mein 
Kind, die Sonne bewegt sich nicht. Verliere nicht den Mut, bilde dir stets dein eigenes Urteil und laß die andern ruhig lachen.' [...] Das war die erste wirkliche Freude, die ich in meinem Leben genoß. ${ }^{11}$

Es ist also auf der Reise, durch den Blick aus dem Fenster des fahrenden Schiffes, dass der kleine Junge auf grundlegende Fragen und Antworten, die das ganze Universum betreffen, gebracht wird und zugleich lernt, dass man für sich allein denken muß, ohne den anderen einfach nachzugeben. Entscheidend in dieser Szene ist die Bewegung, die Veränderung der Perspektive und die verschiedenen Standpunkte, die ein Beobachter-Ich sowie andere Figuren gegenüber demselben Gegenstande einnehmen können. Die Erkenntnis ist also ein Kind der Bewegung, eine Frucht des Reisens, das von so zentraler Bedeutung für den Ich-Erzähler ist, weil aus dieser Mobilität zugleich sich verändernde Blickwinkel und damit eine Multiperspektivität ensteht. Die äußere wie auch die innere Bewegung sind von zentraler Bedeutung, um den gesamten Text der nachfolgenden Histoire de ma vie verstehen $\mathrm{zu}$ können: Sie erst eröffnen jene verschiedenartigen Perspektiven auf die Welt, welche im literarischen Reisebericht wirkungsvoll in Szene gesetzt werden.

Dabei ist auch hier der Genuss, das Genießen, die Freude an der Erkenntnis ein ganz zentraler Faktor, der das Ich prägt und gerade mit Blick auf die Zukunft eine nur schwer zu störende und noch schwerer zu zerstörende Festigkeit allem Darzustellenden verleiht. Erkenntnis ist ein ebenso lustvoller Prozess wie die Sexualität, welche auf diesen Seiten recht freizügig ausgelebt werden kann. Die Histoire de ma vie ist ein genießender Text, ein texte de plaisir, der lustvoll niedergeschrieben und lustvoll gelesen werden kann. Dies ist ein Aspekt des von uns verfolgten Verhältnisses zwischen Reisen und Schreiben, auf den wir an dieser Stelle erstmals stoßen und - ganz im Stile von Hugo Friedrich - von einem 'genießenden Schreiben' sprechen können.

Doch nicht allein das Dionysische, sondern auch das Apollinische ist auf diesen Seiten von Beginn an, ab dieser Szene einer ersten Reise mit der Mutter, gegenwärtig. Damit wird die Reisebewegung gleichsam zum Erkenntnismotor eines Denkens und eines Schreibens (wie auch eines Lesens), das sich beständig in Bewegung weiß und alten Vorurteilen die eigene Er-Fahrung des Ich entgegenstellt. Das Reisen ist mit Erkenntnis und Freude, mit Wissen und Lust und Lust am Wissen gepaart. Nichts vermag den stetigen Erkenntnisprozeß des Ich-Erzählers aufzuhalten. In seiner Freiheit, in der Freiheit seiner Bewegungen, wird lustvolle Erkenntnis zum Ziel eines Subjekts, das sich unabschließbar um seine Objekte dreht.

11 Casanova, Giacomo: Geschichte meines Lebens, Bd. 1, S. $87 \mathrm{f}$. 